\title{
APLIKASI FUZZY ADAPTIVE MINIMUM SPANNING TREE (F-AMST) UNTUK PENGELOMPOKAN PARIWISATA KABUPATEN/KOTA PROVINSI SUMATERA BARAT
}

\author{
SUCI ANISA SYUHADA, NARWEN, ZULAKMAL \\ Program Studi S1 Matematika, \\ Fakultas Matematika dan Ilmu Pengetahuan Alam, Universitas Andalas, \\ Kampus UNAND Limau Manis Padang, Indonesia. \\ email : suci.annisa.syuhada@gmail.com
}

Diterima 17 Februari 2020 Direvisi 7 Maret 2020 Dipublikasikan 29 April 2020

\begin{abstract}
Abstrak. Teori graf dapat digunakan dalam bidang pariwisata, dalam hal ini daerah pariwisata dikelompokkan sehingga dapat mewujudkan integrasi pariwisata yang efektif dari setiap objek pada kelompokkanya masing-masing. Pada penelitian ini analisis data yang digunakan adalah fuzzy logic control metode Mamdani. Proses pengelompokan dilakukan dengan menggunakan Fuzzy Adaptive Minimum Spanning Tree (F-AMST) dan diperoleh hasil pengelompokan yang optimal menggunakan indeks Context Independent Optimality and Partiality Properties (COP) tertinggi dengan terbentuknya empat kelompok dari 19 kabupaten/kota di Provinsi Sumatera Barat.
\end{abstract}

Kata Kunci: Fuzzy Adaptive minimum spanning tree, Mamdani, Pengelompokan

\section{Pendahuluan}

Salah satu aplikasi dari teori graf khususnya graf fuzzy adalah bidang pariwisata. Teori graf dapat digunakan untuk mengelompokkan daerah pariwisata sehingga dapat mewujudkan integrasi sumber daya pariwisata yang efektif dari setiap objek pada kelompoknya masing-masing [5]. Dalam sebuah artikel ilmiah, Gao. Wei, dkk. (2017) telah melakukan penelitian bagaimana membuat perencanaan dan pengembangan pengelompokan daerah pariwisata yang membantu pemerintah dalam pengambilan keputusan. Penelitian ini bertujuan untuk mengelompokkan kabupaten/kota di Provinsi Sumatera Barat berdasarkan data sektor pariwisata menggunakan Fuzzy Adaptive Minimum Spanning Tree (F-AMST).

\section{Fuzzy Adaptive Minimum Spanning Tree (F-AMST)}

\subsection{Logika dan Himpunan Fuzzy}

Konsep himpunan fuzzy muncul dari ketidakjelasan atau kesamaran dalam variabel linguistik yang diperkenalkan oleh Professor Zadeh. Ide tersebut merupakan peru- 
muman dari teori himpunan tegas (crisp) yaitu penggabungan antara pendekatan kualitatif dengan kuantitatif [7].

\subsection{Fuzzy Inference System (FIS) Metode Mamdani}

Sistem ini berfungsi untuk mengambil keputusan melalui inferensi berdasarkan logika fuzzy. Inferensi adalah proses penggabungan banyak aturan berdasarkan data yang tersedia. Pada penelitian ini metode yang digunakan adalah metode Mamdani. Metode Mamdani diperkenalkan oleh Ebrahim Mamdani pada tahun 1975. Metode Mamdani merupakan salah satu metode yang sangat fleksibel dan memiliki toleransi pada data yang ada, metode ini memiliki kelebihan yaitu lebih intuitif dan diterima oleh banyak pihak. Untuk mendapatkan nilai output dari metode Mamdani Inference system melalui 4 tahap sebagai berikut [8]:

(1) Fuzzyfikasi

Fuzzyfikasi adalah proses untuk merubah input dari himpunan tegas (crisp) menjadi himpunan fuzzy dengan fungsi keanggotaannya masing-masing.

(2) Penerapan fungsi implikasi

Penerapan fungsi implikasi memuat aturan-aturan berupa implikasi fuzzy. Fungsi implikasi yang diterapkan digunakan untuk menghubungkan variabel input dengan variabel output.

(3) Komposisi aturan (rule)
(a) Metode maximum
(b) Metode additive
(c) Metode probabilistik or

(4) Defuzzyfikasi

Defuzzyfikasi adalah penerjemah hasil himpunan fuzzy sebagai output dalam nilai tegas (crisp). Nilai tegas inilah yang kemudian diaplikasikan dalam bentuk pengambilan keputusan.

\subsection{Model F-AMST}

Minimum Spanning Tree (MST) banyak digunakan dalam analisis kelompok (cluster analysis). Analisis kelompok bertujuan untuk membagi $n$ objek menjadi $m$ kelompok, dimana objek-objek yang berada pada satu kelompok memiliki ukuran kemiripan data yang tinggi sedangkan dengan objek pada kelompok lain memiliki ukuran kemiripan data yang relatif rendah.

Ukuran kemiripan data salah satunya adalah ukuran jarak Euclidean. Dalam melakukan analisis kelompok pada minimum spanning tree (MST) salah satu ukuran jarak yang dapat digunakan adalah ukuran jarak Euclidean. Jarak Euclidean dirumuskan sebagai berikut [8]:

$$
d(i, j)=\sqrt{\sum_{l=1}^{a}\left(x_{i} l-x_{j} l\right)^{2}},
$$

dimana $d(i, j)$ adalah jarak Euclidean data $i$ ke $j, x_{i} l$ adalah variabel $l$ data $x_{i}$, $x_{j} l$ adalah variabel $l$ data $x_{j}$ dan $a$ adalah banyak variabel. 


\subsubsection{Pembentukan F-MST}

Graf Minimum Spanning Tree (MST) diperoleh dengan menggunakan algoritma Prim. Algoritma Prim adalah suatu algoritma di dalam teori graf yang bertujuan untuk menentukan minimum spanning tree dari suatu graf berbobot. Pemilihan bobot minimum pada algoritma Prim berdasarkan titik yang diambil. Berdasarkan [3] Langkah-langkah dalam menentukan MST menggunakan algoritma Prim adalah sebagai berikut :

(1) Pilih sembarang titik di graf $G$, masukkan ke dalam $T=\left\{\left(x_{1}\right)\right\}$,

(2) Cari titik $\left(x_{2}\right)$ yang bertetangga dengan $x_{1}$ dengan jarak minimum, sehingga diperoleh $T=\left\{\left(x_{1}, x_{2}\right)\right\}$,

(3) Ulangi langkah 2, yaitu mencari titik yang bertetangga pada titik dalam $T$ dengan jarak minimum dan tidak membentuk cycle sampai semua titik termuat dalam $T$ dengan sisi sebanyak $n-1$.

Setelah minimum spanning tree terbentuk, selanjutnya adalah membentuk Fuzzy Minimum Spanning Tree (F-MST) dengan cara mengganti bobot sisi minimum spanning tree (MST) yang telah terbentuk menjadi bobot sisi fuzzy [5]. Berikut adalah rumus bobot sisi fuzzy antara objek satu dengan objek lainnya :

$$
e_{i j}=w_{i} \cdot w_{j} \cdot\left(\frac{1}{d(i, j)}\right),
$$

dimana $w_{i}$ adalah bobot titik fuzzy data ke- $i, w_{j}$ adalah bobot titik fuzzy data ke- $j$ dan $d(i, j)$ adalah jarak antara titik $i$ dan $j$. Bobot titik fuzzy ditentukan oleh Fuzzy Inference System (FIS) dengan metode Mamdani. Semakin kecil jarak Euclidean antara kedua objek maka semakin besar bobot sisi fuzzy antara keduanya.

\subsubsection{Partisi F-MST}

Setelah graf $G$ yang merupakan Fuzzy Minimum Spanning Tree (F-MST) terbentuk, akan dilakukan penghapusan sisi secara rekursif dari F-MST sehingga graf $G$ menghasilkan beberapa subtrees $G_{1}, G_{2}, \ldots, G_{m}$ dengan metode Spatial ' $k$ ' luster analysis by tree edge removal (SKATER) [6].

Metode SKATER adalah salah satu metode regionalisasi untuk analisis pengelompokan spasial yang mentransformasikan data-data suatu wilayah menjadi graf-graf partisi. Pemilihan cut-set berdasarkan kriteria jumlah kekuatan kontak fuzzy pada graf $G_{m}$ yang disebut Dense $\left(G_{m}\right)$. Dense $\left(G_{m}\right)$ didefinisikan sebagai jumlah dari bobot sisi fuzzy setiap titik ke titik pusat graf $G_{m}$. Titik pusat graf $G_{m}$ dinotasikan dengan $x_{\bar{i}}$, Dense $\left(G_{m}\right)$ dihitung dengan cara :

$$
\begin{gathered}
\operatorname{Dense}\left(G_{m}\right)=\Sigma_{i \in G_{m}} e_{i \bar{i}}, \\
x_{\bar{i}}=\frac{\sum_{i \in G_{m}} w_{i}}{\left|G_{m}\right|},
\end{gathered}
$$

dimana $e_{i \bar{i}}$ adalah bobot sisi fuzzy $x_{i}$ ke $x_{\bar{i}}, x_{\bar{i}}$ adalah titik pusat graf $G_{m}, w_{i}$ 
adalah bobot titik fuzzy data ke- $i$ dan $\left|G_{m}\right|$ adalah jumlah titik di $G_{m}$. Berikut ini adalah langkah-langkah untuk memperoleh partisi Fuzzy Minimum Spanning Tree (F-MST) menggunakan metode SKATER :

(1) Jumlah kelompok berada pada interval $[2, \sqrt{n}]$, dimana $n$ adalah jumlah objek penelitian dan jumlah kelompok dinotasikan dengan $m$.

(2) Mulai dari graf $G_{m}=G_{0}$, dimana $G_{0}=F-M S T$.

(3) Untuk setiap $G_{m}$, pilih $e_{i j}$ yang memiliki bobot sisi fuzzy minimum sebagai cut-set.

(4) $G_{m}$ dapat dipartisi menjadi $G_{1}$ dan $G_{2}$ jika memenuhi kondisi $\left(\operatorname{dense}\left(G_{1}\right)>\right.$ dense $(G))$ dan $\left(\operatorname{dense}\left(G_{2}\right)>\operatorname{dense}(G)\right)$ atau $\left(\max \left\{\operatorname{dense}\left(G_{1}\right)\right.\right.$, dense $\left.\left(G_{2}\right)\right\}>$ dense $(G))$ dan $\left(\min \left\{\operatorname{dense}\left(G_{1}\right)\right.\right.$, dense $\left.\left.\left(G_{2}\right)\right\}<\operatorname{dense}(G)\right)$.

(5) Jika $G_{m}<m$ (jumlah kelompok yang ditentukan) maka ulangi langkah 3 dan 4.

\subsection{Efektivitas dan Penyesuaian Pengelompokan}

Solusi pengelompokan optimal diperoleh dari evaluasi untuk semua kemungkinan jumlah kelompok yang berbeda menggunakan indeks Context - Independent Optimality and Partiality Properties (COP) [5]. Ini adalah proses adaptif dari model Fuzzy Adaptive Minimum Spanning Tree (F-AMST). Indeks COP didefinisikan dengan rumus berikut:

$$
C O P=\frac{\left(\Sigma_{j=1}^{|G|} \frac{\text { intra }_{G_{m}}}{\text { inter }_{G_{m}}}\right)}{|G|},
$$

dimana intra $_{G_{m}}$ adalah rata-rata kekuatan kontak fuzzy antar titik di $G_{m}$, inter $_{G_{m}}$ adalah bobot sisi fuzzy minimum antar titik dalam $G_{m}$ dengan titik luar $G_{m}$ dan $|G|$ adalah jumlah kelompok.

intra $_{G_{m}}$ dihitung dengan cara :

$$
\operatorname{Intra~}_{G_{m}}=\Sigma_{i \in G_{m}} \frac{e_{i \bar{i}}}{\left|G_{m}\right|},
$$

dimana $e_{i \bar{i}}$ adalah bobot sisi fuzzy data $i$ ke data titik pusat dan $\left|G_{m}\right|$ adalah jumlah titik di $G_{m}$.

Bobot sisi fuzzy minimum antar titik dalam $G_{m}$ dengan titik luar $G_{m}\left(\right.$ Inter $\left._{G_{m}}\right)$ menggunakan persamaan :

$$
\text { Inter }_{G_{m}}=\min _{i \in G_{m} g \notin G_{m}} e_{i g} .
$$

Semakin besar nilai indeks Context-Independent Optimality and Partiality Properties (COP) pada suatu jumlah kelompok tersebut mengakibatkan semakin konsisten dengan tujuan pengelompokan.

\section{Hasil dan Pembahasan}

Setiap kabupaten/kota yang diamati pada penelitian ini dimisalkan sebagai titik yang disajikan pada tabel di bawah ini : 


\begin{tabular}{|c|l|c|l|}
\hline Titik & \multicolumn{1}{|c|}{ Kabupaten/Kota } & Titik & \multicolumn{1}{|c|}{ Kabupaten/Kota } \\
\hline$x_{1}$ & Kota Bukittinggi & $x_{11}$ & Kabupaten Tanah Datar \\
$x_{2}$ & Kota Payakumbuh & $x_{12}$ & Kabupaten Agam \\
$x_{3}$ & Kota Padang Panjang & $x_{13}$ & Kabupaten Kepulauan Mentawai \\
$x_{4}$ & Kota Sawahlunto & $x_{14}$ & Kabupaten Padang Pariaman \\
$x_{5}$ & Kota Padang & $x_{15}$ & Kabupaten Dharmasraya \\
$x_{6}$ & Kota Solok & $x_{16}$ & Kabupaten Sijunjung \\
$x_{7}$ & Kota Pariaman & $x_{17}$ & Kabupaten Solok \\
$x_{8}$ & Kabupaten Solok Selatan & $x_{18}$ & Kabupaten Pesisir Selatan \\
$x_{9}$ & Kabupaten Pasaman & $x_{19}$ & Kabupaten Pasaman Barat \\
$x_{10}$ & Kabupaten Lima Puluh Kota & & \\
\hline
\end{tabular}

Tabel 1 Nama Kabupaten/Kota Provinsi Sumatera Barat

Berdasarkan variabel penelitian, jarak antar kabupaten/kota akan dihitung menggunakan jarak Euclidean. Perhitungan jarak Euclidean dilakukan secara manual dengan rumus yang tertera pada Persamaan (2.1). Titik kabupaten/kota yang diberikan pada Tabel 1, maka kabupaten/kota direpresentasikan dalam bentuk graf $G$ dimana kabupaten/kota merupakan titik dan sisi adalah jarak Euclidean sebagai ukuran kemiripan data antara satu kabupaten/kota dengan kabupaten/kota lainnya di Provinsi Sumatera Barat.

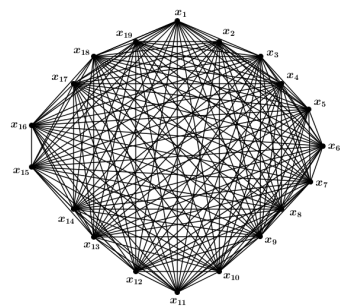

Gambar 1. Graf $G$ merupakan ilustrasi 19 titik Kabupaten/Kota

\subsection{Pengelompokan Menggunakan Model F-AMST}

Langkah awal adalah menentukan Minimum Spanning Tree (MST) menggunakan algoritma Prim untuk graf $G$ yang terbentuk dari titik-titik kabupaten/kota dan sisi adalah jarak Euclidean.

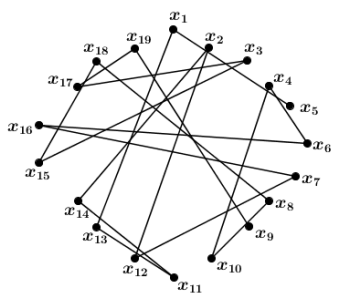

Gambar 2. MST dari graf $G$ menggunakan algoritma Prim 
204 Suci Anisa Syuhada dkk.

Setelah Minimum Spanning Tree (MST) diperoleh, selanjutnya akan dilakukan perancangan logika fuzzy Mamdani untuk menentukan bobot titik fuzzy setiap kabupaten/kota yang ada di Provinsi Sumatera Barat menggunakan Matlab R2013a $[1]$.

Hasil perhitungan bobot titik fuzzy untuk setiap kabupaten/kota dapat dilihat pada tabel di bawah ini :

\begin{tabular}{|l|c|l|c|}
\hline \multicolumn{1}{|c|}{ Kabupaten/Kota } & $\begin{array}{c}\text { Bobot } \\
\text { Fuzzy }\end{array}$ & Kabupaten/Kota & $\begin{array}{c}\text { Bobot } \\
\text { Fuzzy }\end{array}$ \\
\hline Kota Bukittinggi & 6,21 & Kabupaten Tanah Datar & 6,38 \\
Kota Payakumbuh & 5 & Kabupaten Agam & 6,28 \\
Kota Padang Panjang & 5 & Kabupaten Kepulauan Mentawai & 5,73 \\
Kota Sawahlunto & 6,29 & Kabupaten Padang Pariaman & 6,4 \\
Kota Padang & 8,63 & Kabupaten Dharmasraya & 5 \\
Kota Solok & 5 & Kabupaten Sijunjung & 5 \\
Kota Pariaman & 5 & Kabupaten Solok & 6,22 \\
Kabupaten Solok Selatan & 5 & Kabupaten Pesisir Selatan & 2,65 \\
Kabupaten Pasaman & 1,61 & Kabupaten Pasaman Barat & \\
Kabupaten Lima Puluh Kota & 6,05 & & \\
\hline
\end{tabular}

Tabel 2 : Hasil perhitungan bobot titik fuzzy menggunakan Matlab R2013a

Setelah diperoleh bobot titik fuzzy untuk setiap kabupaten/kota, selanjutnya akan dihitung bobot sisi fuzzy dengan menggunakan Persamaan (2.2).

\subsection{Partisi $F-M S T$}

Berikut adalah langkah-langkah dalam mempartisi F-MST menggunakan metode Spatial 'K'luster Analysis by Tree Removal (SKATER) :

(1) Jumlah kelompok berada pada interval $[2, \sqrt{19}]$. Jumlah kelompok yang ditentukan adalah empat kelompok.

(2) Setiap kabupaten/kota masuk dalam minimum spanning tree yang telah ditentukan sebelumnya. Selanjutnya adalah proses pemilihan sisi yang akan dihapus dari F-MST. SKATER melakukan partisi rekursif dari F-MST untuk mendapatkan pengelompokan. Untuk membentuk partisi dari 19 kabupaten/kota menjadi empat daerah pengelompokan, dilakukan penghapusan $(4-1)$ sisi dari F-MST. Masing-masing akan menghasilkan kelompok yang berbentuk graf pohon. Pembentukan partisi dari 19 titik kabupaten/kota dilakukan dengan cara:

1. Mulai dari graf $G_{m}=G_{0}$, dimana $G_{0}=F-M S T$.

2. Untuk setiap $G_{m}$, pilih $e_{i j}$ yang memiliki bobot sisi fuzzy minimum sebagai cut-set.

3. $G_{m}$ dapat dipartisi menjadi $G_{1}$ dan $G_{2}$ jika memenuhi kondisi (dense $\left.\left(G_{1}\right)>\operatorname{dense}(G)\right)$ dan $\left(\operatorname{dense}\left(G_{2}\right)>\operatorname{dense}(G)\right)$ atau $\left(\max \left\{\operatorname{dense}\left(G_{1}\right)\right.\right.$, $\left.\left.\operatorname{dense}\left(G_{2}\right)\right\}>\operatorname{dense}(G)\right)$ dan $\left(\min \left\{\operatorname{dense}\left(G_{1}\right)\right.\right.$, dense $\left.\left.\left(G_{2}\right)\right\}<\operatorname{dense}(G)\right)$.

4. Jika $G_{m}<4$ maka ulangi langkah 2 dan 3 .

Perhitungan Dense $\left(G_{m}\right)$ dari partisi F-MST oleh pemilihan sisi yang dihapus disajikan pada Tabel 3. 


\begin{tabular}{llll}
\hline & $G_{1}(0)$ & & \\
F-MST $(34,4455)$ & $G_{2}(40,6421)$ & $G_{3}(0)$ & \\
& & $G_{4}(48,4867)$ & $G_{5}(28,1374)$ \\
& & $G_{6}(57,1973)$
\end{tabular}

Tabel 3 : Hasil perhitungan kekuatan kontak fuzzy pada kelompok

Perhitungan Dense dari kelompok-kelompok yang terbentuk pada tabel diatas akibat dari penghapusan sisi menggunakan metode Spatial ' $k$ ' luster analysis by tree edge removal (SKATER).

\subsection{Efektivitas dan Penyesuaian Pengelompokkan}

Kelompok-kelompok yang terbentuk dievaluasi menggunakan indeks (COP). Masing-masing jumlah kelompok yang terbentuk akan dihitung indeks COPnya untuk menentukan jumlah kelompok yang optimal terbentuk. Semakin tinggi nilai dari indeks COP maka jumlah kelompok yang terbentuk akan semakin bagus. Nilai dari indeks COP ditentukan untuk setiap kemungkinan jumlah kelompok. Perhitungan nilai indeks COP dapat dilakukan dengan menggunakan rumus pada Persamaan (2.5).

\begin{tabular}{cccc}
\hline Jumlah kelompok & 2 & 3 & 4 \\
\hline COP & 73,3084 & 61,7359 & 119,4669 \\
\hline
\end{tabular}

Tabel 4 : Perhitungan indeks COP untuk masing-masing kelompok

Fungsi indeks COP yang disajikan pada bagian 2.8 digunakan untuk mencari efektifitas solusi pengelompokan. Solusi pengelompokan yang berbeda diilustrasikan dalam Tabel 4. Menurut perhitungan indeks COP pada Tabel 4. Diperoleh nilai COP maksimum ketika jumlah kelompok adalah empat. Oleh karena itu solusi pengelompokan dengan jumlah kelompok empat menjadi pengelompokan optimal dari 19 kabupaten/kota di Provinsi Sumatera Barat. Hasil pengelompokan dengan jumlah pengelompokan adalah 4 disajikan pada tabel dibawah ini :

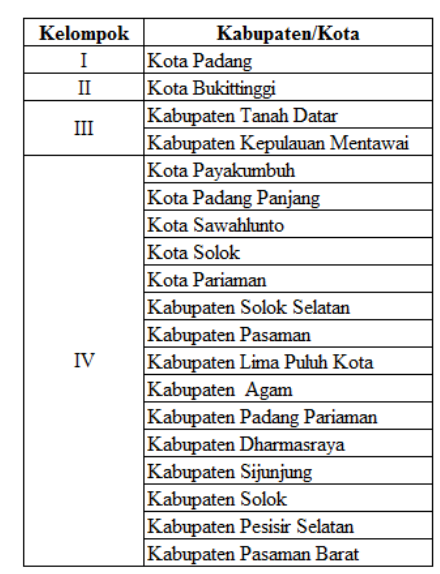

Tabel 5: Hasil pengelompokan degan empat kelompok 


\section{Kesimpulan}

(1) Hasil pengelompokan yang tebentuk dari kabupaten/kota adalah 2 kelompok, 3 kelompok dan 4 kelompok. Pembentukan jumlah kelompok optimal adalah kelompok yang memiliki nilai indeks COP tertinggi, yaitu pembentukan 4 kelompok dengan nilai indeks COP sebesar 119,4669.

(2) Setiap kabupaten/kota dapat berkerjasama dalam kelompoknya masing-masing untuk mewujudkan integrasi sumber daya pariwisata yang efektif. Berikut adalah hasil pengelompokan yang optimal berdasarkan nilai indeks COP :

(a) Kelompok 1 : Kota Padang.

(b) Kelompok 2 : Kota Bukittinggi.

(c) Kelompok 3 : Kabupaten Tanah Datar dan Kabupaten Kepulauan Mentawai.

(d) Kelompok 4 : Kota Payakumbuh, Kota Padang Panjang, Kota Sawahlunto, Kota Solok Kota Pariaman, Kabupaten Solok Selatan, Kabupaten Pasaman, Kabupaten Lima Puluh Kota, Kabupaten Agam, Kabupaten Padang Pariaman, Kabupaten Dharmasraya, Kabupaten Sijunjung, Kabupaten Solok, Kabupaten Pesisir Selatan dan Kabupaten Pasaman.

\section{Ucapan Terima Kasih}

Penulis mengucapkan terima kasih kepada Ibu Dr. Lyra Yulianti, Bapak Prof. Dr. I Made Arnawa, dan Ibu Dr. Arrival Rince Putri yang telah memberikan bimbingan, masukan dan saran sehingga penelitian ini dapat diselesaikan dengan baik.

\section{Daftar Pustaka}

[1] Agus Naba, Eng. 2009. Belajar Cepat Fuzzy Logic Menggunakan Matlab. Andi Offset, Yogyakarta

[2] Badan Pusat Statistik. 2019. Provinsi Sumatera Barat Dalam Angka 2019. Badan Pusat Statistik. Sumatera Barat

[3] Bondy, J.A dan Murty, U.S.R. 1976. Graph Theory with Application. The Macmillan Press LTD, London

[4] Dinas Pariwisata. 2018. Laporan Akuntabilitas Kinerja Pemerintah (LAKIP). Dinas Pariwisata. Sumatera Barat

[5] Gao, W., Qiuluan, Z., Zi, L., Dianshuang, W., Xiaohui, D. 2017. Modelling and Application of Adaptive Minimum Spanning Tree in Tourism Agglomeration Area Division. Elsevier Science Publishing. 143 : 317-326

[6] Lage, J. P., Renato, M. A., Edna, A. R. 2001. A Minimal Spanning Tree Algorithm Applied to Spatial Cluster Analysis. Elsevier Science Publishing. 702-30 : $123-970$

[7] Ross, T. J. 2010. Fuzzy Logic With Engineering Application Third Edition. Wiley, Mexico

[8] Zimmermann, H. J. 2001. Fuzzy Set Theory and Its Application Fourth Edition. Kluwer Academic, New York 